\title{
Li-O2 Piller için $\alpha$-MnO2/Grafen/KNT Nanokompozit Elektrotlarının Üretimi ve Karakterizasyonu
}

\author{
*11Miraç Alaf, ${ }^{2}$ Ubeyd Toçoğlu, ${ }^{3}$ Hatem Akbulut \\ ${ }^{1}$ Bilecik Şeyh Edebali Üniversitesi, Mühendislik Fakültesi, Metalurji ve Malzeme Mühendisliği, Bilecik \\ Miraç.alaf@bilecik.edu.tr \\ ${ }^{2}$ Sakarya Üniversitesi, Mühendislik Fakültesi, Metalurji ve Malzeme Mühendisliği, Sakarya \\ utocoglu@sakarya.edu.tr \\ ${ }^{3}$ Sakarya Üniversitesi, Mühendislik Fakültesi, Metalurji ve Malzeme Mühendisliği, Sakarya \\ akbulut@sakarya.edu.tr
}

Geliş Tarihi: 2017-11-05 Kabul Tarihi: 2017-12-27

\begin{abstract}
$\ddot{O} \mathbf{z}$
$\mathrm{Bu}$ çalışmada Li-O2 pilleri için elektrot malzemesi $\alpha-\mathrm{MnO} 2 / \mathrm{Grafen} / \mathrm{KNT}$ nanokompozitleri üretilmiş ve karakterize edilmiştir. Grafen Hummer metodu ile üretilmiş ve tabakalar arası boşluk yapıcı olarak karbon nano tüp ilavesi yapılmıştır. $\alpha-\mathrm{MnO} 2$ nano çubuklar sentezlenerek $\alpha-\mathrm{MnO} 2 / \mathrm{Grafen} / \mathrm{KNT}$ nanokompozitleri vakum filtrasyon yöntemi ile kağıt halinde elektrot olarak üretilmiştir. Üç farklı oranda ilave edilen $\alpha-\mathrm{MnO} 2$ nano çubukları ile elektrotların yapısal karakterizasyonu FESEM, XRD kullanılarak ve elektrokimyasal karakterizasyonu da ECC-hava test hücreleri ile yapılmıştır.
\end{abstract}

Anahtar kelimeler: Grafen, $\alpha-\mathrm{MnO} 2$ nano çubuklar, kompozit, enerji depolama

\section{Production and Characterization of $\alpha-\mathrm{MnO2} / \mathrm{Graphene/CNT}$ Nanocomposite Electrodes for Li-O2 Batteries}

\author{
*1Miraç Alaf, 2Ubeyd Toçoğlu, 3Hatem Akbulut \\ 1Bilecik Sheikh Edebali University, Faculty of Engineering, Metallurgical and Materials Engineering, Bilecik \\ mirac.alaf@bilecik.edu.tr \\ 2Sakarya University, Faculty of Engineering, Metallurgy and Materials Engineering, Sakarya \\ utocoglu@sakarya.edu.tr \\ 3Sakarya University, Faculty of Engineering, Metallurgy and Materials Engineering, Sakarya \\ akbulut@sakarya.edu.tr
}

\begin{abstract}
In this study, of $\alpha-\mathrm{MnO} 2 / \mathrm{Graphene/CNT}$ nanocomposites were produced and characterized as electrode for $\mathrm{Li}-\mathrm{O} 2$ batteries. Graphene was produced with Hummer method and carbon nano tubes were added to graphene as spacers between layers. $\alpha-\mathrm{MnO} 2$ nanorods were synthesized and $\alpha-\mathrm{MnO} 2 / \mathrm{Graphene/CNT}$ nanocomposites were fabricated by vacuum filtration technique as a paper electrode. $\alpha-\mathrm{MnO} 2$ nanorods were added to composite at three different rates and electrodes were characterized by FESEM and XRD. The electrochemical characterization was carried out in ECC-air test cells.
\end{abstract}

Keywords: Graphene, $\alpha-\mathrm{MnO} 2$ nanorods, composite, energy storage

\section{GíRiş}

Modern dünyanın büyüyen küresel enerji ihtiyac1; petrol, kömür ve doğalgaz gibi fosil yakıtların aksine daha çevreyle dost ve daha yenilenebilir büyük ölçekli enerji kaynaklarına yönelmeyi sevk etmektedir. $\mathrm{CO}_{2}$ emisyonunda ki artış ve petrolün sınırlı olması da temiz enerji kaynakları bulmayı gerektirmektedir. $\mathrm{Bu}$ kapsamda piller, süper kapasitörler ve yakıt hücreleri dahil enerji üretimi, dönüşümü ve depolanması için kullanılan elektrokimyasal sistemler önemli bir rol

*Sorumlu Yazar: ${ }^{1}$ Bilecik Şeyh Edebali Üniversitesi, Mühendislik Fakültesi, Metalurji ve Malzeme Mühendisliği, Bilecik, mirac.alaf@bilecik.edu.tr 
oynamaktadır. Taşınabilir elektronik devreler (bilgisayar, ak1llı telefon vb.) ve otomotiv (elektrikli veya hibrit araçlar) uygulamaları dahil geleceğin enerji depolama sistemlerinde özellikle şarj olabilen lityum pillerin kilit bir rol üstleneceği bilinmektedir [1]. Lityum piller yüksek enerji ve güç yoğunluğunun eşsiz kombinasyonuna sahiptir. $\mathrm{Bu}$ özellik lityum pilleri taşınabilir elektronik devreler, elektrikli aletler ve elektrikli veya hibrit araçlar için tercih edilen bir teknoloji yapar. Elektrikli araçlar petrolle çalışan araçların yerini aldığında Li-iyon piller $\mathrm{CO}_{2}$ emisyonunu önemli derecede azaltacaktır. Lityum pillerin yüksek enerji verimliliği bu pillerin rüzgar, güneş, jeotermal ve diğer yenilenebilir enerji kaynaklarından elde edilen enerjinin kalitesini artırmada kullanılan elektrik nakil uygulamalarında da kullanılmasını sağlamaktadır. $\mathrm{Bu}$ yüzden lityum piller hem endüstri hem akademik çalışmalar için ilgi çekicidir [2].

Piller içinde en yüksek teorik enerji yoğunluğuna sahip (11.248 $\mathrm{Wh} \mathrm{kg}^{-1}$ ) $\mathrm{Li}-\mathrm{O}_{2}$ pilleri olarak bilinen Li-hava pilleri Abraham tarafindan ilk olarak 1996 yılında sunulmuştur [3]. Li-hava pili genellikle bir metalik Li anot, bir aprotik çözücü içinde çözünmüş bir lityum tuzundan oluşan bir elektrolit, bir katı seperatör ve bir poroz oksijen geçiren katottan oluşmaktadır [4]. Deşarj esnasında katotta indirgenen oksijen (dışarıdaki havadan gelen) ile $\mathrm{Li}-$ metal anottan gelen $\mathrm{Li}^{+}$ iyonu $\mathrm{Li}_{2} \mathrm{O}_{2}$ oluşturmak için birleşir (oksijen redüksiyon reaksiyonu-ORR);

$2 \mathrm{Li}^{+}+\mathrm{O}_{2} \uparrow+2 \mathrm{e}^{-} \rightarrow \mathrm{Li}_{2} \mathrm{O}_{2}$

Şarj esnasında, $\mathrm{Li}_{2} \mathrm{O}_{2}, \mathrm{Li}^{+}$ve $\mathrm{O}_{2}$ 'ye geri döner (oksijen evolüsyon reaksiyonu-OER) [5].

$$
\mathrm{Li}_{2} \mathrm{O}_{2} \rightarrow 2 \mathrm{Li}^{+}+\mathrm{O}_{2} \uparrow+2 \mathrm{e}^{-}
$$

Bir hekzagonal latiste $\mathrm{sp}^{2}$ bağları ile bağlanmış karbon atomlarının tek bir tabakası olan grafen yüksek elektronik iletkenlik, geniş teorik yüzey alanı $\left(2630 \mathrm{~m}^{2} \mathrm{~g}^{-1}\right)$, mükemmel yapısal esneklik ve yüksek yüzey/hacim oranından dolayı enerji depolama alanında kullanım için harika bir potansiyele sahiptir [6]-[8]. Grafenin yüzeyi kimyasal reaksiyonlar için aktif bölge olarak görev yapabilen çok sayıda hatalı bölge ve kenar içerir. Bu karakteristik özellikler grafeni enerji depolama sistemleri için çok uygun bir malzeme yapar [9]. $\mathrm{Bu}$ avantajlarının yanında grafen tabakaları indirgendikleri esnada güçlü van der Waals etkileşimi ve artan hidrofobiklikten dolayı geri dönüşümsüz olarak agrege olma eğilimi gösterirler. $\mathrm{Bu}$ yüzden grafenin elde edilebilen yüzey alanı, iletkenlik ve spesifik kapasite değerleri beklenenin çok altında kalır. Grafen tabakalarının kimyasal redüksiyonu esnasında aglemerasyonunu minimize etmek için kullanılan stratejilerden biri tabakaların arasına bir boşluk yapıc1 malzeme (karbon nano tüp, fulleren, karbon karası vb.) ilave etmektir. Bu sadece tabakalar arası mesafeyi arttırmaya değil aktif malzemenin iletkenliğini ve yüzey alanını arttırmaya da katkı sağlar[10].

Katalist olarak grafen-metal oksit heterojen malzemeler OER/ORR reaksiyonlarının kinetiklerini geliştirmede yeni bir yol sağlar [11], [12]. $\alpha-\mathrm{MnO}_{2}$ oksijen redüksiyon reaksiyonları (ORR) için umut vaat etmektedir. Düşük maliyetli bir alternatif için çalışmalarda mangan oksit elementel bolluğu, alkalin içinde yüksek aktivitesi ve zehirli olmamasından ötürü dikkat çekmektedir. Grafen ve $\alpha-\mathrm{MnO}_{2}$ çekici özelliklerinden ötürü $\mathrm{Li}-\mathrm{O}_{2}$ pillerde katalist olarak kullanılır [13]. Mevcut çalışmada, grafen Hummer metodu ile üretilmiştir. Üretilen grafenin tabakaları arası aglomerasyonunu önlemek için üretim esnasinda uygun anyonik ve katyonik yüzey aktif maddeler kullanılmıştır. Grafene daha sonra tabakaların arasına bir boşluk yapıcı malzeme olan karbon nano tüp (KNT) ilave edilerek tabakalar arası mesafe, aktif malzemenin iletkenliği ve yüzey alanı arttırılmıştır. Üretilen $\alpha-\mathrm{MnO}_{2}$ nano çubukları ile grafen kompozit haline getirilerek heterojen elektrotlar $\mathrm{Li}-\mathrm{O}_{2}$ pilleri için vakum filtrasyon yöntemi ile üretilmiştir ve karakterize edilmiştir.

\section{DENEYSEL ÇALIŞMALAR}

$\mathrm{Li}-\mathrm{O}_{2}$ pilleri için elektrotların üretimi 3 adımda yapılmıştır; i) Grafenin sentezlenmesi, ii) $\alpha-\mathrm{MnO}_{2}$ nano çubukların sentezlenmesi, iii) Elektrotların hazırlanması. Pulcuk grafitten grafen sentezlenmesi için Hummer metodu kullanılmıştır. Grafit pulcukları $\mathrm{H}_{2} \mathrm{SO}_{4}$ ve $\mathrm{HNO}_{3}$ çözeltisinde 2 saat karıştırıldıktan sonra saf su ile yıkanıp kurutulmuş ve daha sonra $800^{\circ} \mathrm{C}$ 'de 120 sn arası 1sıl işleme maruz bırakılmıştır. $\mathrm{Bu}$ ön işlemli grafit $\mathrm{NaNO}_{3}$ ile birlikte $\mathrm{H}_{2} \mathrm{SO}_{4}$ ile birlikte yaklaşık iki saat karıştırılmıştır. Karışım sıcaklığı $-20^{\circ} \mathrm{C}$ ye kadar düşürülerek $\mathrm{KMnO}_{4}$ ilavesi yapılmıştır. Ardından sıcaklık $98{ }^{\circ} \mathrm{C}$ 'ye getirilip karıştırmaya devam edilmiştir. Oda sıcaklığına inildikten sonra saf su ve $\mathrm{H}_{2} \mathrm{O}_{2}$ ilave edilmiştir. Burada $\mathrm{H}_{2} \mathrm{O}_{2}$ 'nin ilave edilmesinin nedeni çözeltide çözünmemiş olarak bulunan kalıntı permanganat yapısını mangan iyonlarına indirgemektir. Elde edilen çözelti süzüldükten sonra gram başına $100 \mathrm{ml} \%$ 30'luk $\mathrm{HCl}$ çözeltisi ile yıkanmıştır. Ardından pH 6-6,5 olana kadar saf su ile yıkanıp santrifüjle süzülmüştür. Elde edilen ürün grafen oksit (GO) olarak adlandırılmaktadır. 
$\alpha-\mathrm{MnO}_{2}$ nano çubukların üretim prosedüründe, 3,16 $\mathrm{g} \mathrm{KMnO}_{4}$ ve 5,07 $\mathrm{g} \mathrm{MnSO}_{4} 80 \mathrm{ml}$ saf su içinde karıştırılarak çözülmüştür. $\mathrm{Bu}$ çözelti Teflon otoklava alınarak $140^{\circ} \mathrm{C}^{\prime} \mathrm{de} \quad 30 \mathrm{dk}$ mikrodalga sentez firınında tutulmuştur. Ardından otoklav oda sıcaklığına kendi kendine soğutulmuştur. Çökelti süzülmüş ve kalıntı kalmayana ve $\mathrm{pH}^{\prime}$ ' nötr olana kadar saf su ile defalarca yıkanmıştır. Çökelen $\mathrm{MnO}_{2}$ 'ler vakumlu etüvde $80^{\circ} \mathrm{C}^{\prime}$ de kurutulmuştur.

Kompozit elektrot üretim prosesinde, $\alpha-\mathrm{MnO}_{2}$, KNT ve grafen oksit saf su içine konulmuş ve ultrasonik prosesörde (sonikatör) yüzey aktif madde ilavesi de yapılarak homojenlik sağlanana kadar 1 saat süre ile karıştırılmıştır. Suda partiküllerin homojen dağılması sağlandıktan sonra çözelti vakum filtrasyon sisteminde 0,22 $\mu \mathrm{m}$ por boyutlu PVDF membran üzerinde süzülmüştür. Vakum filtrasyondan sonra serbest (free-standing) ve esnek elektrot membran üzerinden soyulmuş ve vakumlu etüvde $40^{\circ} \mathrm{C}^{\prime} \mathrm{de}$ kurutulmuştur.

Kompozitlerin bileşimlerini ve yapılarını belirlemek için $\mathrm{Cu}-\mathrm{K} \alpha$ radyasyonu ile $\mathrm{X}-1$ şını (Rigaku D/MAX2000) difraktometresi kullanılmıştır. Yüzey morfolojisini incelemek için taramalı elektron mikroskobu kullanılmıştır (SEM, JEOL 6335F). Elektrokimyasal karakterizasyon için ECC-hava test hücreleri argon ile doldurulmuş eldivenli kutuda hazırlanmıştır. Üretilen kompozitler katot, lityum metal folyo anot, $1 \mathrm{M}^{\prime}$ lik $\mathrm{LiPF}_{6}$ NMP çözeltisi elektrolit ve cam fiberler seperatör olarak kullanılmıştır. ECC-hava test hücrelerinin şarjdeşarj işlemi 1-4,5 V aralığında sabit akım yoğunluğunda MTI BST8-MA Battery Analyzer cihazı ile yapılmıştır. Dönüşümlü voltametri $(\mathrm{CV})$ ve elektrokimyasal empedans spektroskopisi (EIS) çalışmaları Gamry Instrument Version 5.67 cihazı ile yapılmıştır. Çevrimsel voltametri eğrileri $1,5-4,5 \mathrm{~V}$ aralığında $0,2 \mathrm{mVs}^{-1}$ tarama hızında elde edilmiştir. Empedans spektrumları $10 \mathrm{mV}$ şiddetinde (genliğinde) bir sinüs dalgasının uygulanması ile $0,01-100 \mathrm{kHz}$ frekans aralığında alınmıştır.

\section{SONUÇLAR VE TARTIŞMA}

Şekil 1 sentezlenen grafen oksit ve $\alpha-\mathrm{MnO}_{2}$ 'e ait XRD analizlerini ve alan emisyonlu taramalı elektron mikroskobu (FESEM) görüntülerini vermektedir. Şekil 1a üretilen grafen oksite ait XRD paternini göstermektedir 11.5 derecedeki pik 00-026-1080 JCPDS kart numarası ile belirtilen karbon pikine ve (002) düzlemine aittir. 26,4 derecede bulunan pikin şiddetinin çok düşük olması kalıntı grafit kalmadığını işaret etmektedir [14] . Şekil 1b'de sunulan grafen oksitten alınmış FESEM fotoğrafi grafitin bazal düzlemlerinin birbirlerinden başarılı bir şekilde ayrılarak elde edilen ince grafen oksit tabakasını göstermektedir. Şekil 1c sentezlenen $\alpha-\mathrm{MnO}_{2}{ }^{\prime} \mathrm{e}$ ait XRD paternidir ve 01-081-1947 JCPDS kart numaralı Mangan oksit-alfa fazı ile uyuşmaktadır [15]. Herhangi bir empirüteye rastlanmayan patern ürünün yüksek saflıkta olduğunu göstermektedir. Şekil 1d üniform bir şekilde üretilmiş $60-80 \mathrm{~nm}$ çaplı ve yaklaşık $2 \mu \mathrm{m}$ uzunluğundaki $\alpha-\mathrm{MnO}_{2}$ nanoçubuklarına ait FESEM görüntüsüdür.

Üretilen grafen oksit (GO) ve $\alpha-\mathrm{MnO}_{2}, \mathrm{KNT}$ ilavesi ile birlikte kompozit haline getirilerek elektrot üretimleri gerçekleşmiştir. Ağırlıkça grafen oksit (GO) ve KNT miktarı sabit tutularak $\alpha-\mathrm{MnO}_{2}$ miktarına göre üç farklı oranda kompozitler üretilmiştir. İçerikleri $\alpha-\mathrm{MnO}_{2}: \mathrm{GO}: \mathrm{KNT} 1: 1: 1,2: 1: 1$ ve $3: 1: 1$ olacak şekilde numuneler sırasılyla $1-\mathrm{MnO}_{2}, 2-\mathrm{MnO}_{2}$ ve $3-\mathrm{MnO}_{2}$ şeklinde kodlanmıştır. Şekil 2 üretilen kompozit elektrotlara ait XRD paternlerini vermektedir. $26,2^{\circ}$ deki pik karbon nanotüplerin pikini göstermektedir [16]. b ve d deki ana pikler $\left(12.88^{\circ}, 18.29^{\circ}, 28.91^{\circ}\right.$ ve $37.73^{\circ}$ deki pikler) tetragonal fazdaki $\alpha-\mathrm{MnO}_{2}$ fazını göstermektedir. Kompozitlerin üretimi esnasında kimyasal olarak (hidrazin hidrat ile) grafene indirgenmiş grafen oksit piki görülmemektedir. Tamamen grafene indirgenme işlemi gerçekleştiğinden grafen oksit piki görülmemektedir [17].

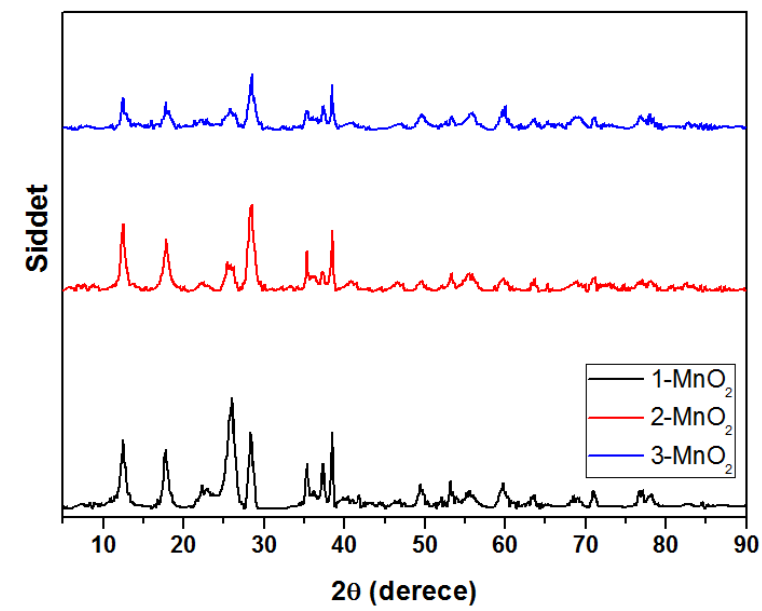

Şekil 2. Kompozit elektrotların XRD paternlerini 


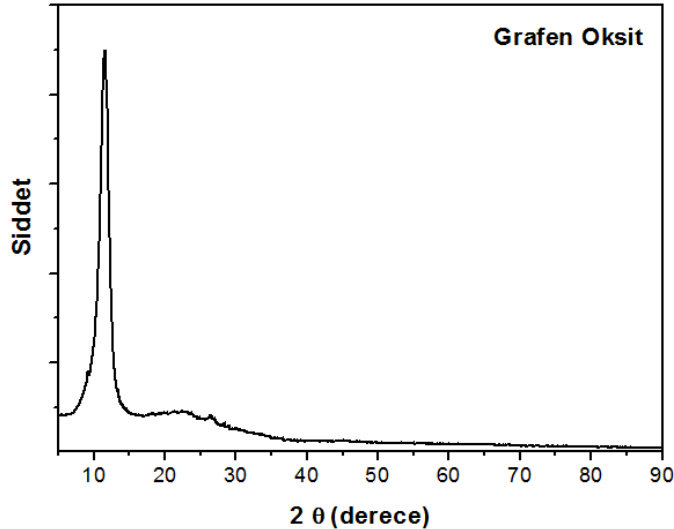

(a)

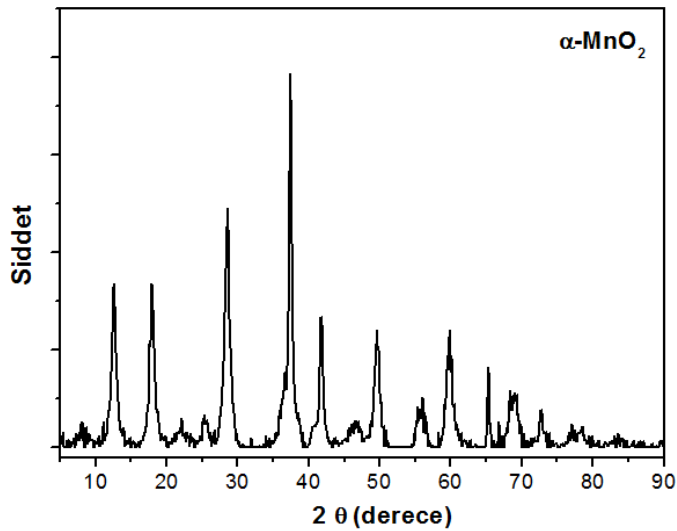

(c)

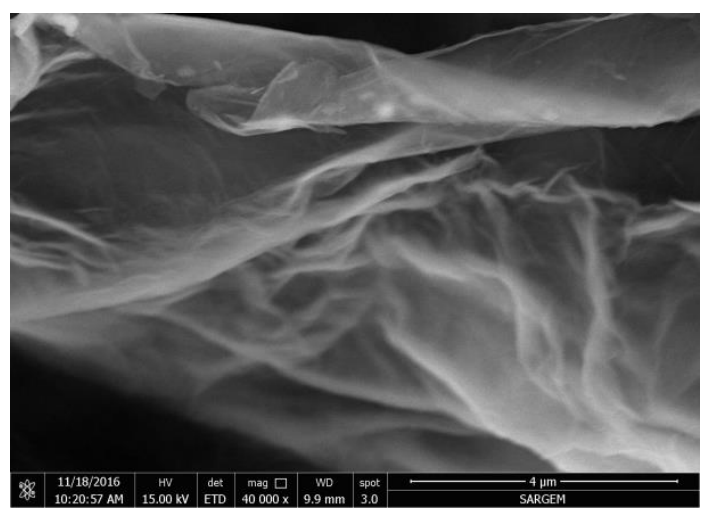

(b)

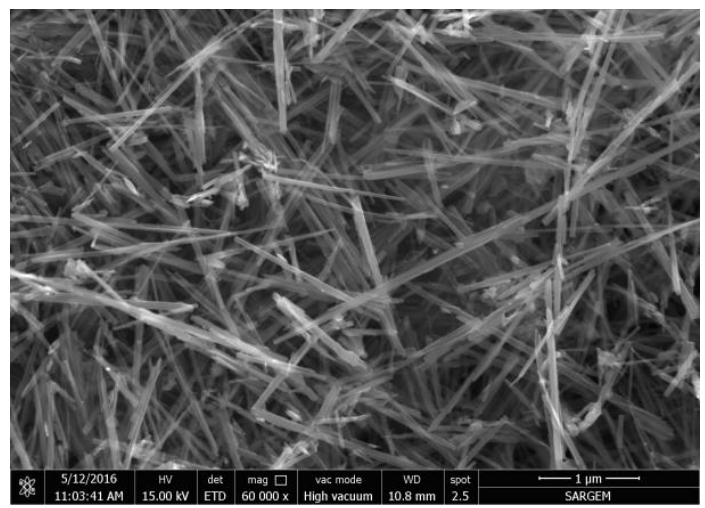

(d)

Şekil 1. a) Grafen oksitin XRD paterni b) Grafen oksitin FESEM fotoğrafı c) $\alpha-\mathrm{MnO}_{2}$ nano çubukların XRD paterni d) $\alpha-\mathrm{MnO}_{2}$ nano çubukların FESEM fotoğrafı

Şekil 3a üretilen elektrotlara ait kesit görüntüsünü sunmaktadır. $80 \mu \mathrm{m}$ kalınlığında üretilen elektrot herhangi bir metal altlık üzerine kaplama gerektiren geleneksel elektrotlarına aksine üretildiği haliyle direkt olarak kullanıma imkan sağlamaktadır. Şekil $3 \mathrm{~b}, 3 \mathrm{c}$ ve $3 \mathrm{~d}$ sirasiyla $1-\mathrm{MnO}_{2}, 2-\mathrm{MnO}_{2}$ ve $3-\mathrm{MnO}_{2}$ numunelerine ait FESEM görüntüleridir. Aglomere olmaya eğilimli grafen tabakaları arasına $\mathrm{MnO}_{2}$ ve KNT ilave edilmesi ile aglomerasyon engellenmiş, tabakaların arası mesafe arttırılmıştır. $\alpha-\mathrm{MnO}_{2}$ nano çubuklarının homojen olarak dağılmış olduğu görüntülerden anlaşılmaktadır.

Üretilen elektrotların elektrokimyasal testleri ECC-hava hücresi içinde yapılmıştır. Şekil 4 her bir elektrottan üretilmiş $\mathrm{Li}-\mathrm{O}_{2}$ pillerinin ilk 5 çevrim için dönüşümlü voltametri $(\mathrm{CV})$ eğrilerini vermektedir. Çevrimsel voltametri eğrileri 1,5-4,5 V aralığında $0,2 \mathrm{mVs}^{-1}$ tarama hızında elde edilmiştir. Katodik taramada elde edilen pikler $\quad \mathrm{Li}-\mathrm{O}_{2}$ hücrelerindeki ORR reaksiyonlarından beklendiği gibidir. ORR reaksiyonlarındaki ana reaksiyon (1) nolu reaksiyon şeklindedir. Katodik taramalarda 2,5 V değerindeki redüksiyon piki süper oksitin oluşumuna işaret etmektedir [1]. Bir elektron transfer reaksiyonu $\mathrm{LiO}_{2}$ oluşumunda baskın reaksiyondur. Kararsiz $\mathrm{LiO}_{2}$ de $\mathrm{Li}_{2} \mathrm{O}_{2}$ 'ye dekompose olur. $\mathrm{Bu} \mathrm{Li}_{2} \mathrm{O}_{2}$ deşarj reaksiyonunun bir ürünü olarak $\mathrm{Li}^{+}$ve $\mathrm{O}_{2}{ }^{\prime}$ ye dönüşür (Reaksiyon (2)). $\mathrm{Bu}$ reaksiyonun piki anodik taramadaki 3,0-3,5 aralığındaki piklerdir. 


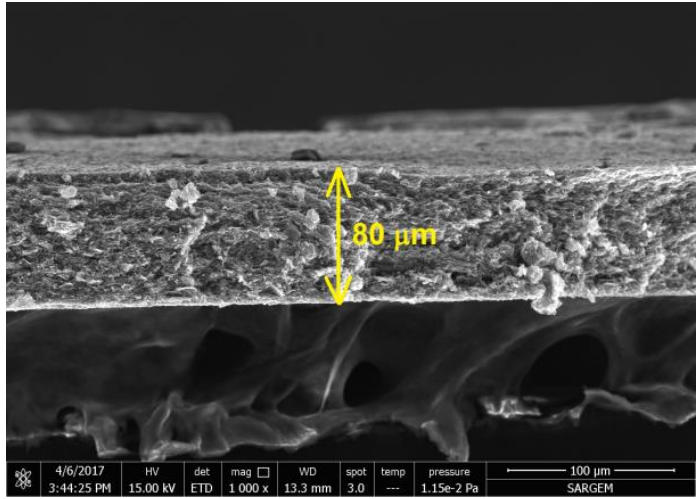

(a)

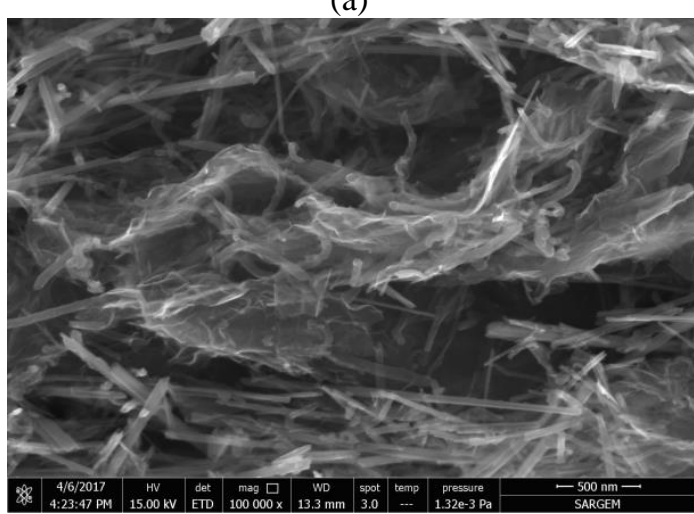

(c)

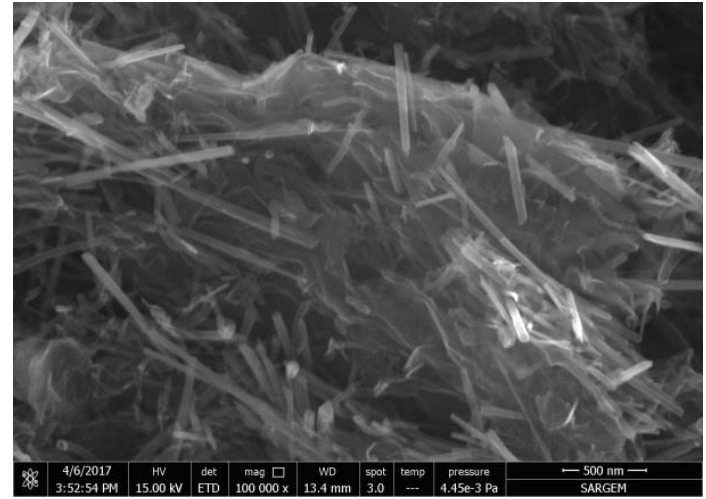

(b)

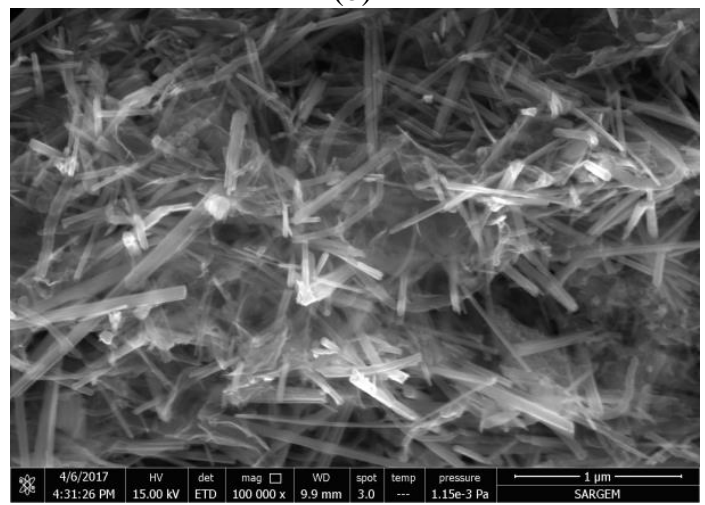

(d)

Şekil 3. a) Elektrotun kesit görüntüsü b) $1-\mathrm{MnO}_{2}$ elektrotunun FESEM görüntüsü c) $2-\mathrm{MnO}_{2}$ elektrotunun FESEM görüntüsü d) $3-\mathrm{MnO}_{2}$ elektrotunun FESEM görüntüsü

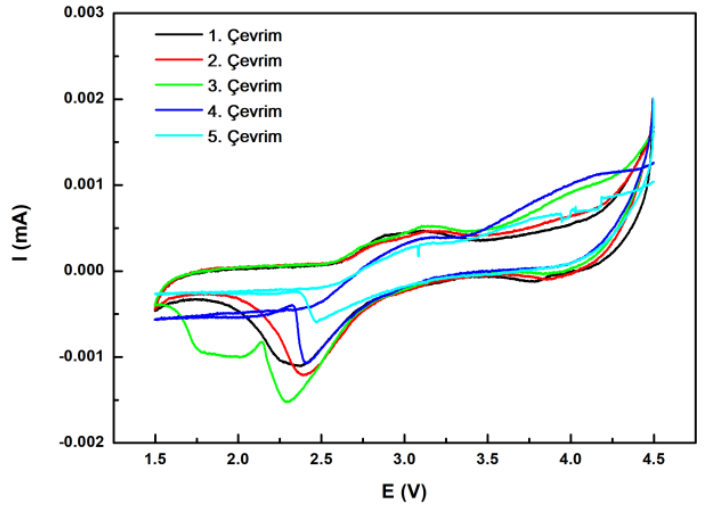

(a)

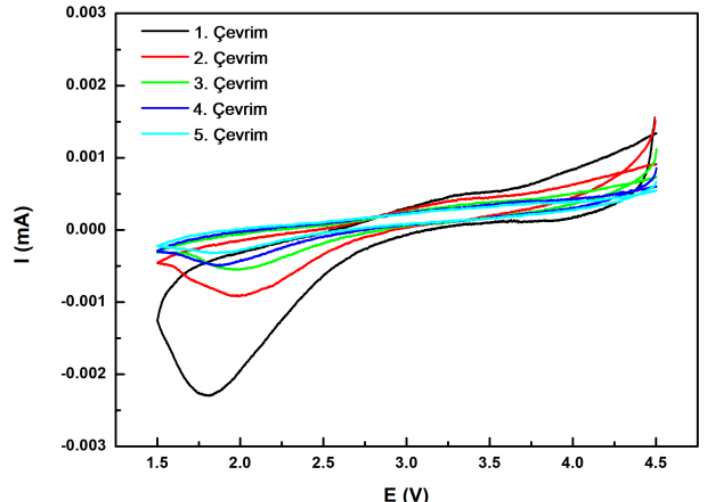

(b)

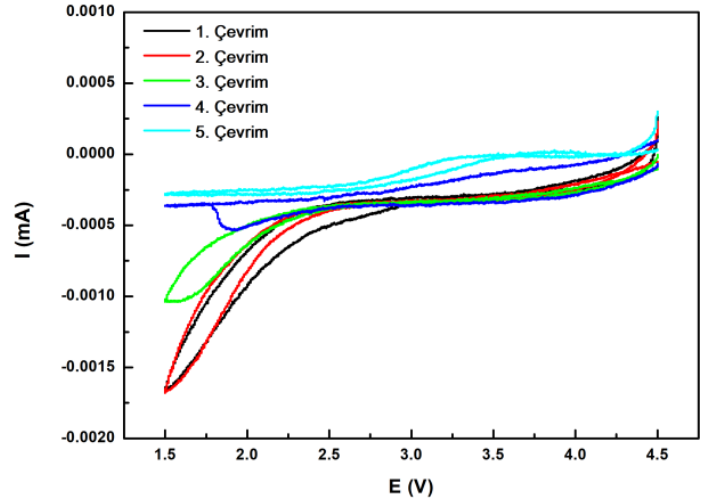

(c)

Şekil 4. a) $1-\mathrm{MnO}_{2}$, b) 2- $\mathrm{MnO}_{2}$ ve c) $3-\mathrm{MnO}_{2}$ kodlu elektrotlara ait $\mathrm{CV}$ eğrileri 
Şekil 5 1- $\mathrm{MnO}_{2}, 2-\mathrm{MnO}_{2}$ ve $3-\mathrm{MnO}_{2}$ kodlu elektrotlara ait spesifik deşarj kapasitesi ve çevrim sayısı grafiğini göstermektedir. 10 çevrim sonunda grafen, $1-\mathrm{MnO}_{2}, 2-\mathrm{MnO}_{2}$ ve $3-\mathrm{MnO}_{2}$ kodlu elektrotlar için sırasıyla 490 mAh g-1, 471 mAh g-1, 484 mAh g-1'lik kapasiteler elde

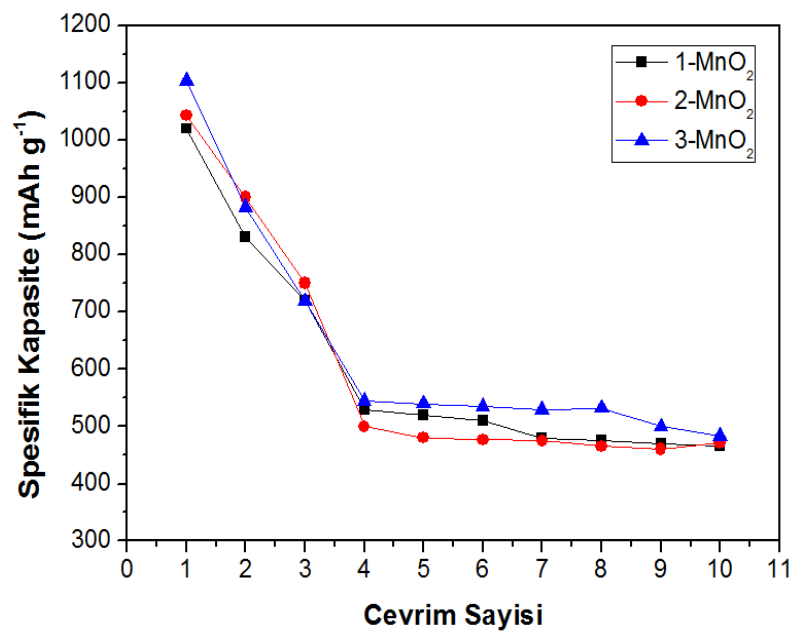

Şekil 5. Elektrotların spesifik kapasite eğrileri

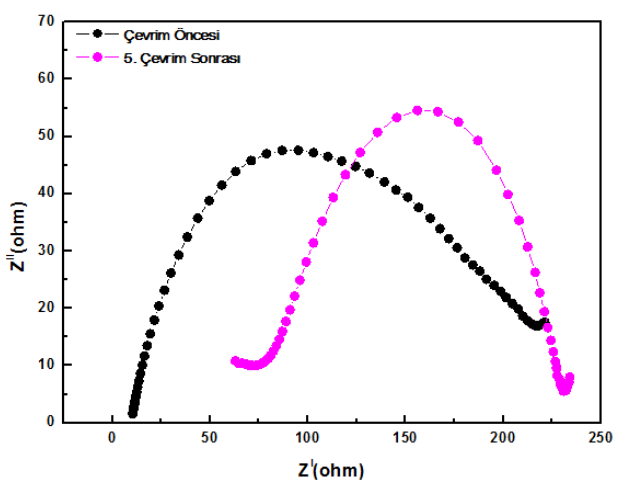

(a) edilmiştir. Kapasite kaybı çevrim esnasındaki geri dönüşümsüz ürünlerin oluşmasından kaynaklanmaktadır. $\mathrm{Li}-\mathrm{O}_{2}$ pillerinde çevrim ömrü önemli ölçüde elektrolitin dekompozisyonuna bağlıdır [18].

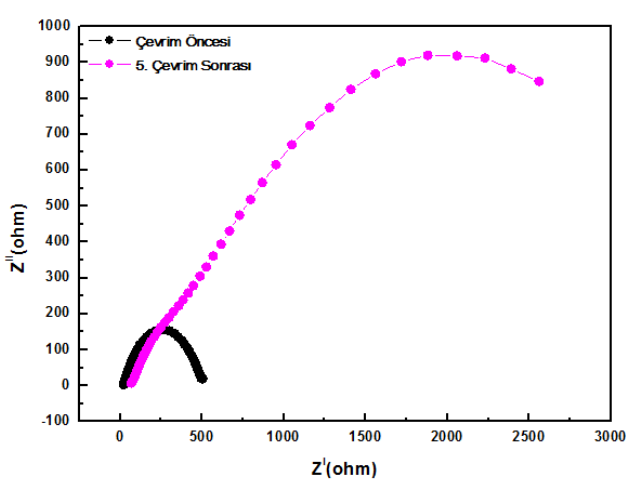

(b)

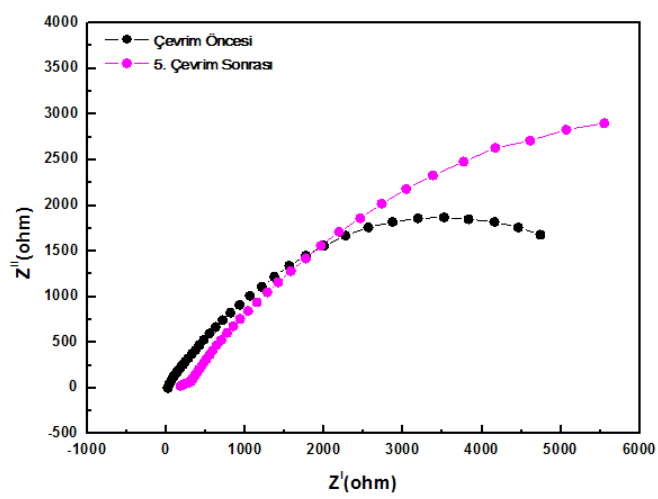

(c)

Şekil 6. a) $1-\mathrm{MnO}_{2}$, b) 2- $\mathrm{MnO}_{2}$ ve c) $3-\mathrm{MnO}_{2}$ kodlu elektrotlara ait çevrim öncesi ve 5 çevrim sonrası Nyquist eğrileri

Şekil 6 1- $\mathrm{MnO}_{2}, 2-\mathrm{MnO}_{2}$ ve 3- $\mathrm{MnO}_{2}$ kodlu elektrotlara ait çevrim öncesi ve 5. çevrim sonrası elektrokimyasal impedans spektroskopisi analizi ile elde edilmiş Nyquist eğrilerini göstermektedir. Çevrim sonrası alınan eğrilerde iki tane yarı-çember görülmektedir. Yüksek frekanstaki ilki elektrolit ile elektrot arasındaki direnci göstermektedir. İkinci yarı-çember ise şarj transfer direnci ile ilgilidir [19]. 


\section{TEŞEKKÜR}

Yazarlar bu çalışma için 2015-02.BŞEÜ.03-05 numaralı proje kapsamında destek sağlayan Bilecik Şeyh Edebali Üniversitesi Rektörlüğü Bilimsel Araştırma Projeleri Koordinatörlüğ̈̈'ne teşekkür eder.

\section{KAYNAKÇA}

[1]D. Capsoni, M. Bini, S. Ferrari, E. Quartarone, and P. Mustarelli, "Recent advances in the development of Li-air batteries," J. Power Sources, vol. 220, pp. 253-263, 2012.

[2]N. Nitta, F. Wu, J. T. Lee, and G. Yushin, "Liion battery materials: Present and future," Mater. Today, vol. 18, no. 5, pp. 252-264, 2015.

[3]M. J. Song and M. W. Shin, "Fabrication and characterization of carbon nanofiber@mesoporous carbon core-shell composite for the Li-air battery," Appl. Surf. Sci., vol. 320, pp. 435-440, 2014.

[4]A. Kraytsberg and Y. Ein-Eli, "Review on Liair batteries - Opportunities, limitations and perspective," J. Power Sources, vol. 196, no. 3, pp. 886-893, 2011.

[5]J. Liu, R. Younesi, T. Gustafsson, K. Edström, and J. Zhu, "Pt/ $\alpha-\mathrm{MnO} 2$ nanotube: A highly active electrocatalyst for Li-O2 battery," Nano Energy, vol. 10, pp. 19-27, 2014.

[6]W. Xiao, Z. Wang, H. Guo, X. Li, J. Wang, S. Huang, and L. Gan, "Fe2O3 particles enwrapped by graphene with excellent cyclability and rate capability as anode materials for lithium ion batteries," Appl. Surf. Sci., vol. 266, pp. 148-154, 2013.

[7]Y. Wen, C. Huang, L. Wang, and D. HulicovaJurcakova, "Heteroatom-doped graphene for electrochemical energy storage," Chinese Sci. Bull., vol. 59, no. 18, pp. 2102-2121, 2014.

[8]G. Gnana kumar, Z. Awan, K. Suk Nahm, and J. Stanley Xavier, "Nanotubular MnO2/graphene oxide composites for the application of open airbreathing cathode microbial fuel cells," Biosens. Bioelectron., vol. 53, pp. 528-534, 2014.

[9]H. Zhou, X. Yang, J. Lv, Q. Dang, L. Kang, Z. Lei, Z. Yang, Z. Hao, and Z. H. Liu,

"Graphene/MnO2 hybrid film with high capacitive performance," Electrochim. Acta, vol. 154, pp. 300-307, 2015.
[10]Y. Wimalasiri and L. Zou, "Carbon nanotube/graphene composite for enhanced capacitive deionization performance," Carbon $N$. Y., vol. 59, pp. 464-471, 2013.

[11]L. Zhang, F. Zhang, G. Huang, J. Wang, X. $\mathrm{Du}, \mathrm{Y}$. Qin, and L. Wang, "Freestanding MnO2@carbon papers air electrodes for rechargeable Li-O2 batteries," J. Power Sources, vol. 261, pp. 311-316, 2014.

[12]R. S. Kalubarme, C. H. Ahn, and C. J. Park, "Electrochemical characteristics of graphene/manganese oxide composite catalyst for Li-oxygen rechargeable batteries," Scr. Mater., vol. 68, no. 8, pp. 619-622, 2013.

[13]D. A. Tompsett, S. C. Parker, and M. S. Islam, "Surface properties of $\alpha-\mathrm{MnO}_{2}$ : relevance to catalytic and supercapacitor behaviour," J. Mater. Chem. A, vol. 2, no. 37, pp. 15509-15518, 2014. [14]L. Stobinski, B. Lesiak, A. Malolepszy, M. Mazurkiewicz, B. Mierzwa, J. Zemek, P. Jiricek, and I. Bieloshapka, "Graphene oxide and reduced graphene oxide studied by the XRD, TEM and electron spectroscopy methods," J. Electron Spectros. Relat. Phenomena, vol. 195, pp. 145154, 2014.

[15]A. A. Hlaing and P. P. Win, "The synthesis of $\alpha$-MnO 2 nanorods using hydrothermal homogeneous precipitation," Adv. Nat. Sci. Nanosci. Nanotechnol., vol. 3, no. 2, p. 25001, 2012.

[16]M. Salehi and Z. Shariatinia, "Electrochimica Acta An optimization of $\mathrm{MnO}_{2}$ amount in CNT$\mathrm{MnO} 2$ nanocomposite as a high rate cathode catalyst for the rechargeable Li-O 2 batteries," Electrochim. Acta, vol. 188, pp. 428-440, 2016. [17]M. Jiang, H. He, C. Huang, B. Liu, W. J. Yi, and Z. S. Chao, " $\alpha-\mathrm{MnO}_{2}$ Nanowires/Graphene Composites with High Electrocatalytic Activity for Mg-Air Fuel Cell," Electrochim. Acta, vol. 219, pp. 492-501, 2016.

[18]J. Yuan, J. S. Yu, and B. Sundén, "Review on mechanisms and continuum models of multiphase transport phenomena in porous structures of non-aqueous Li-Air batteries," J. Power Sources, vol. 278, pp. 352-369, 2015.

[19]J. Zang, H. Qian, Z. Wei, Y. Cao, M. Zheng, and Q. Dong, "Reduced graphene oxide supported $\mathrm{MnO}$ nanoparticles with excellent lithium storage performance," Electrochim. Acta, vol. 118, pp. 112-117, 2014. 